\title{
HORIZONTAL EQUITY FOR DISABLED PEOPLE: INCAPACITY FROM ACCIDENT OR ILLNESS
}

\author{
Robert Stephens*
}

The current dual system of benefit provision and service delivery for disabled people has led to substantial horizontal inequities between those on the ACC register and those receiving incometested social security benefits. Whilst there are often distinct differences in the nature of the clientele between these groups, they often have similar requirements, but can receive quite different treatment. The Disability Strategy offers the prospect that a more unified system will be developed, initially in terms of service provision, especially rehabilitation and access to health care. The move to a combined benefit structure raises issues about the fundamental nature of social security, though equality of access to second and third tier benefits should minimise the degree of conflict between earnings-related and flat-rate benefits. From the perspective of disabled people, the major issue is access to non-income support, ranging from access to equipment to health care, education and employment.

\section{INTRODUCTION}

In April 2001, the Labour-Alliance coalition Government launched the New Zealand Disability Strategy. ${ }^{1}$ The aim of the Strategy is for New Zealand to become an inclusive society, eliminating all barriers to people with disabilities from participating in and contributing to society. The Strategy is visionary, and when fully implemented by Government, communities, employers and support agencies will have a significant impact on integrating disabled people into the wider community.

The Strategy recognises that disabled people receive differential treatment, with Objective 7.5 stating that the Strategy will "encourage equity of funding and service provision for people with

* Associate Professor of Public Policy, School of Government, Victoria University of Wellington. E-mail: Bob.Stephens@vuw.ac.nz. Helpful comments on an earlier draft from Tessa Thompson, Office for Disability Issues, and Moira Wilson, Ministry of Social Development, are gratefully acknowledged, but the usual disclaimers apply.

1 Ministry of Health The New Zealand Disability Strategy: Making a World of Difference (Ministry of Health, Wellington, 2001). 
similar needs, regardless of cause of impairment". The differential treatment mainly relates to comparing those who fall under the rubric of the Accident Compensation Corporation (ACC) with those who receive the Invalids Benefit (IB) or Sickness Benefits (SB) administered by the Work and Income section of the Ministry of Social Development (WI). ACC compensation is restricted to those whose incapacity is related to accidents, while IB provides for people with a long-term and severe disability and SB is designed for people with a short-term incapacity. Unless the horizontal inequity between these systems of support for disabled people is addressed, the Strategy will fall short of achieving its objectives.

The establishment of the Office for Disability Issues, with functions of providing information, integration and co-ordination of government policy and service delivery towards people with a disability, is a positive step forward. To date, the Disability Strategy and the profile of the Office for Disability Issues have reflected far more the issues that emerge from an analysis of those on the Sickness and Invalids Benefits (and disabled elderly) than those receiving ACC. But having the same Minister for both ACC and Disability means that an integrative approach can now evolve. ${ }^{2}$ Both policy strands have seen the notion of rehabilitation widened to include social and vocational as well as work objectives, the use of WI work brokers, and through the new Primary Health Organisations, greater equality of access to health care.

The developments are along the lines suggested by a visiting United States scholar, Saucier. ${ }^{3}$ Saucier recognised that the broad framework of the Disability Strategy had been accepted, and drew upon the experience of the ACC to recommend further concrete policy and programme changes for the disabled community: ${ }^{4}$

(1) Promoting independence - a move from service provision that maintains the status quo of disabled people to one with greater expectation of rehabilitation;

(2) Improving the effectiveness of service delivery, with greater coordination and evaluation of existing services;

(3) Simplifying access to comprehensive services, to overcome the separate eligibility and assessment procedures for services.

The above analysis indicates that the issue of horizontal inequity relates to more than just the issue of earnings-related benefits of ACC compared to the flat-rate income-tested SB and IB, which

2 Currently, Hon Ruth Dyson.

3 P Saucier Promoting a National Vision for People with Disabilities: Successful Policies and Enduring Barriers (Ian Axford Fellowship, Wellington, 2002) available at $<$ http://www.fulbright.org.nz $>$ (last accessed 22 November 2004)

4 Saucier, above n 3, 6. 
was recognised at the inception of $\mathrm{ACC}^{5}$ and the later review of social security. ${ }^{6}$ Or, to put the inequity more bluntly: "my friends want to run over me", 7 because the treatment for victims of car accidents has been superior than that for someone experiencing similar functional impairments as a result of multiple sclerosis illness.

The paper starts with a brief comment on the arguments advanced by both the Royal Commissions $^{8}$ to justify two parallel income maintenance systems for people who need support as a result of impairment. ${ }^{9}$ The following section then considers the differences and similarities in client base, trends in benefit receipt and expenditures and service provision between ACC and IB/SB, before considering the issues related to the separate and parallel provision - access to employment, income-related and flat-rate benefits; health and social service provision to offset both on-going and set-up costs; and case management for rehabilitation.

\section{EVOLUTION OF THE DUAL SYSTEM}

As McClure recognised, the two Royal Commissions were almost concurrent, and each acknowledged the significance of their findings for the operation of the other system, but came to quite different conclusions, primarily due to their separate starting points. ${ }^{10}$ Both reports concentrated on the interrelationships between the two benefit systems, not the other discrepancies in service delivery.

The problem facing the Woodhouse Commission ${ }^{11}$ was the inconsistent treatment provided to victims of accidents when in employment. The Commission stated that: "there would be great advantage in the integration of a comprehensive scheme of accident compensation into the present social security framework". ${ }^{12}$ But they then argued that few would accept a flat-rate payment system, as the objective of ACC was to compensate for all consequences of an accident - loss of earnings, pain and suffering - rather than avoidance of economic hardship. The Woodhouse

5 New Zealand Royal Commission of Inquiry into Compensation for Personal Injury Compensation for Personal Injury in New Zealand: Report of the Royal Commission of Inquiry (Government Printer, Wellington, 1967) ["Woodhouse Report"].

6 New Zealand Royal Commission of Inquiry into Social Security Social Security in New Zealand: Report of the Royal Commission of Inquiry [1972] IV AJHR H 53 ["McCarthy Report"].

7 M Trevethick "My Friends Want to Run Over Me" (June 2003) Waikato District Health Board Newsletter.

8 Woodhouse Report, above n 5; McCarthy Report, above n 6.

9 M McClure "A Decade of Confusion: The Differing Directions of Social Security and Accident Compensation 1969-1979" (2003) 34 VUWLR 269 provides a longer review.

10 McClure, above n 9, 273.

11 Woodhouse Report, above n 5.

12 Woodhouse Report, above n 5, 100. 
Commission also recognised that internationally most income maintenance schemes were based on social insurance principles, where benefits vary with prior earnings, doubting "whether a concept for social assistance which was developed in the 1930s should be applied to the compensation needs of the $1970 \mathrm{~s} " .{ }^{13}$ But the Commission did not recognise that apart from pensions, all overseas social insurance schemes were time-limited, with a subsequent fall to a flat-rate, means-tested benefit.

The McCarthy Report on Social Security started from the issue of adequacy of social security benefits: "to ensure that all members of the community have income sufficient to reach an adequate living standard". ${ }^{14}$ The report had a basic premise that many disabled people had not been earners, and thus would not be covered by an earnings-related scheme. They recognised that ACC would overcome the horizontal inequity between injured workers, but would exacerbate the economic anomaly between sickness and accident victims. McClure highlighted the differing concepts of equity between the two reports, ${ }^{15}$ with ACC looking at "a person's contribution, worth, skills or experience"16 while McCarthy was concerned that people were able to offset need and belong to the wider community. ${ }^{17}$

The McCarthy Report argued against extending earnings-related benefits to sickness beneficiaries (no mention is made of invalids beneficiaries) for several inter-related reasons: ${ }^{18}$

(1) Fiscal costs, with at least a doubling of expenditure on sickness benefits, with all the gainers having modest to high incomes;

(2) The anomaly would just be extended to the Unemployment Benefit, as many sickness beneficiaries have the same long-term relationship with employment as those unemployed;

(3) Sickness is often of short duration, with sick leave being initially paid by the employer at full wage rates;

(4) The proposal to raise all benefit levels would reduce the need for earnings-related benefits, especially as the better paid can take out private insurance protection in order to maintain previous living standards.

The Royal Commission on Social Security concluded that: ${ }^{19}$

\footnotetext{
13 Woodhouse Report, above n 5, 105.

14 "McCarthy Report", above n 6, 178.

15 McClure, above n 9, 273

16 McClure, above n 9, 273.

17 "McCarthy Report", above n 6, 62.

18 "McCarthy Report", above n 6, 176-184.

19 "McCarthy Report", above n 6, 183.
} 
The institution of earnings-related sickness payments is not urgent. That could be postponed until the accident compensation scheme is operating and has been tested, and until sufficient time has elapsed to enable better material to be gathered from employers on sickness absences.

Thirty years would seem to be an adequate length of time, but most of the information is still not readily available. Over the years various reports have considered the issue of integration, and the 1989 Budget announced that ACC was to be extended to all forms of incapacity from 1991, but the change of government reversed that decision. ${ }^{20}$

Instead, in 1991 social security benefits were slashed, in real terms, to their pre-1972 level, and eligibility for ACC was tightened and compensation reduced, along with the introduction of competitive private insurance. Until the advent of the Disability Strategy, which may result in integration via the backdoor, the two schemes were drifting further apart, with those restricted by the eligibility rules from ACC forced onto the social security register.

\section{AN ANATOMY OF THE DUAL SYSTEM}

The major issue facing disabled people and their families is not the level of benefit entitlement but the wider issue of appropriate and equitable access to the full range of non-income services, covering access to work, education, rehabilitative equipment, household and vehicle modifications, health care and other social service support such as domestic assistance, personal care and residential support services. In respect of these service delivery issues, the coverage of ACC is more integrated than that of the income-tested benefit system, where separate application is often required for each individual service.

By theoretically providing comprehensive entitlement to all accident victims, ACC covers more than just weekly compensation for employees who are injured. Claims and expenditure also include medical expenses, injury and accident prevention, rehabilitation and home help costs. For incometested benefits, similar expenditures are picked up by a variety of agencies, and a greater degree of personal expenditure. The medical expenses can be: out-of-pocket, subsidised through the Community Services Card (or Primary Health Organisation) for general practitioner visits, through the disability services directorate of the Ministry of Health or as part of District Health Board expenditure. To this can be added much of the Special Education expenditure and aspects of the vocational and employment services expenditure of the Ministry of Social Development. In addition to the first-tier benefits, financial assistance can be given by WI for Disability Allowances, residential support subsidies, Special Benefits and Special Needs grants, all of which are meanstested.

20 Susan St John "Accident Compensation in New Zealand: A Fairer Scheme?" in J Boston, P Dalziel and Susan St John (eds) Redesigning the Welfare State in New Zealand (Oxford University Press, Auckland, 1999) 154, which provides an extended chronology of ACC policy changes. 
In 2002-2003, overall ACC expenditure was just under $\$ 2$ billion, or about 1.5 per cent of Gross Domestic Produce (GDP). Of this, $\$ 950$ million was for rehabilitation benefits and $\$ 752$ million for compensation benefits. By contrast, expenditure on the Sickness Benefit was $\$ 415$ million and Invalids Benefit was $\$ 843$ million (and unemployment benefit $\$ 1,423$ million), and the Ministry of Health allocated $\$ 1300$ million for health disability services. ${ }^{21}$

In 2003 ACC accepted 1.52 million claims, but 90 per cent of these involved medical and other "treatment only" claims, with no financial compensation. Just under half of these registered claims were from non-earners, with a further 2.4 per cent involving vehicle claims. Of the 10 per cent of claims for financial entitlement, some 60.8 per cent of new claims and 46.4 per cent of on-going claims involved weekly earnings-related compensation, accounting for about half of the cost of all entitlement claims. $^{22}$ No payment is made by ACC for the first week off work, with the employer liable to pay if the injury is work-related. As Figure 1 shows, while the majority of ACC entitlement claims last for less than six months, when presumably the claimants have been rehabilitated and returned to their former occupational status, there are a considerable number of long-term claims. These long-term claims account for a significant proportion of expenditure. ${ }^{23}$

The Sickness Benefit is payable to those over 18 who are temporarily unable to work full-time through illness or injury. However, the majority of people in employment who become ill will receive sick leave, usually at full pay, from their employer, so that only those with more serious, longer-lasting illnesses, or without sick leave provisions in their employment contract, will apply for the SB. About 34 per cent of the 34,000 recipients of the SB report a psychiatric illness (with this being the fastest growing category), a further 16 per cent have musculo-skeletal disorders, while 13 per cent have conditions resulting from accidents.

21 Ministry of Social Development The Statistical Report for the Year Ending June 2003 (Ministry of Social Development, Wellington, 2003) 144. ACC data is derived from Accident Compensation Corporation $<$ http://www.acc.co.nz $>$ (last accessed 22 November 2004).

22 Accident Compensation Corporation $<\mathrm{http}: / /$ www.acc.co.nz $>$ (last accessed 22 November 2004).

23 It is recognised that a proportion of the current short-term claimants will unfortunately turn out to be longterm recipients. However, in a mature scheme, which ACC must now be deemed, proportions in each group should remain roughly constant, except for changes in the propensity to rehabilitate. 
Figure $1^{24}$

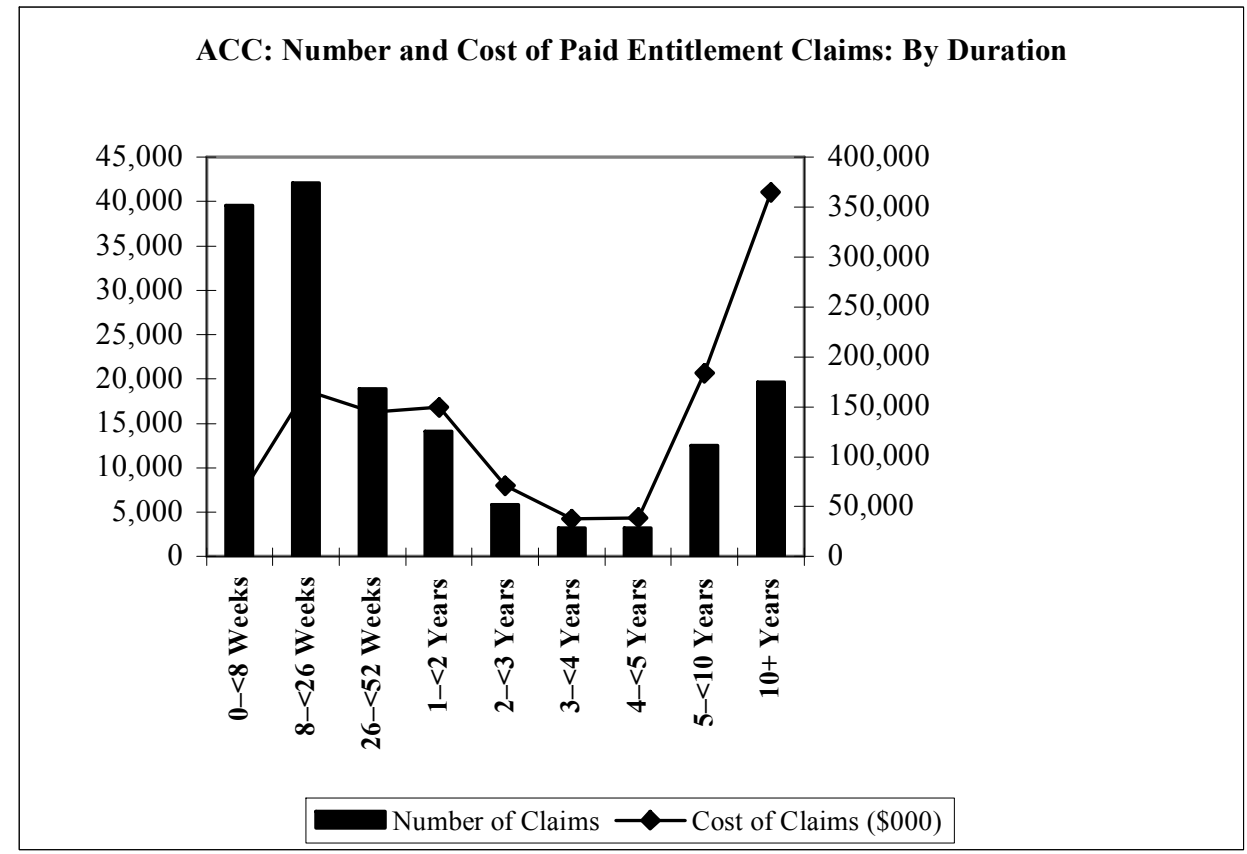

Although there is a relatively high turnover of people on the SB, with inflows and outflows of roughly 40,000 per annum, a significant proportion of sickness beneficiaries have a long duration on the benefit. Figure 2 shows that about one-fifth of sickness beneficiaries are on the benefit for less than 3 months, but one-third are on it for over two years. In 2002, only 13 per cent of those who went off the SB went into paid work, while 53 per cent were transferred to another core social security benefit. Equally, 37 per cent of the inflow had transferred from another core benefit, while roughly the same number had received another core benefit over the last four years. Roughly 70 per cent of sickness beneficiaries receive the Accommodation Supplement, and almost half receive a disability allowance, with a significant proportion receiving weekly Special Benefits or periodic Special Needs grants.

24 Accident Compensation Corporation <http://www.acc.co.nz > (last accessed 22 November 2004). 
Figure $2^{26}$

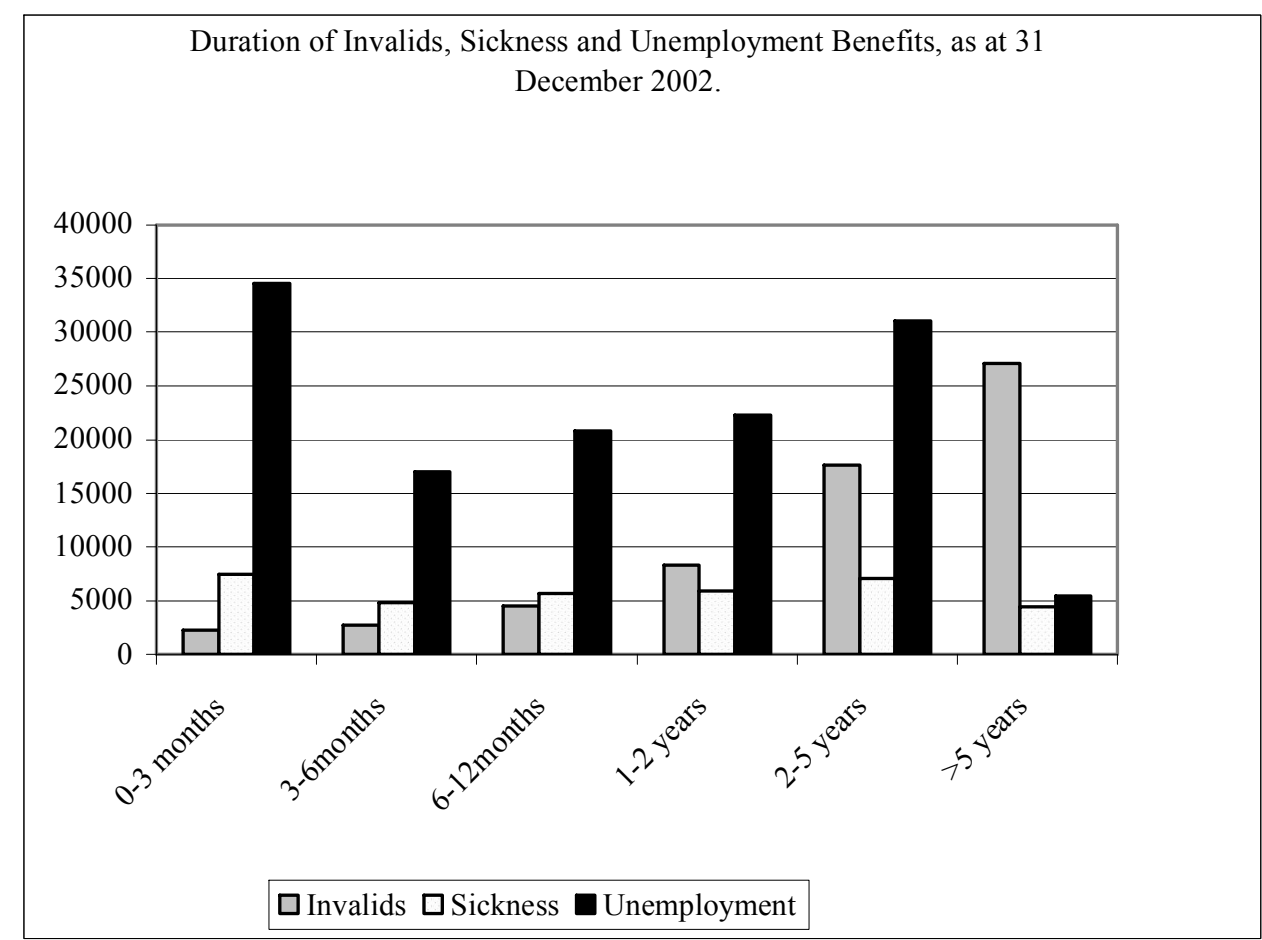

As Figure 3 shows, the number of SB recipients increased steadily from 1986 through to 1996, but has stabilised since then. The growth in numbers receiving the IB has been even faster, with virtually continuous growth and some quickening since 1990, but no downturn in growth, even with the fall in unemployment numbers since 1993. In line with international trends, the proportion of the working-age population on disability benefits has risen from about 1 per cent in the 1970s to 5 per cent in $2002 .^{27}$

The IB is available to those who are permanently and severely restricted in their capacity to work. "Permanent" refers to two years where the client is unable to work 15 hours per week. About 28 per cent of recipients of the IB suffer a psychiatric disorder, a further 16 per cent an intellectual disorder and 13 per cent suffer some form of musculo-skeletal disorder. ${ }^{28}$ While there is a high degree of similarity between the IB and SB populations in terms of impairment type, Figure 2 shows

26 Derived from Ministry of Social Development, above n 21, 24-48.

See generally Ministry of Social Development, above n 21 .

28 Derived from Ministry of Social Development, above n 21, 38-48. 
a different picture in terms of duration. Less than 4 per cent have received the IB for less than three months, and 43 per cent have received that benefit continuously for more than five years.

Clients are often initially placed on the lower-paying SB (or UB) before being re-assessed and placed on the IB. Around 70 per cent of new entrants onto the IB have switched from another core benefit, and only 18 per cent have not received any benefit over the last four years. ${ }^{29}$ Over the last five years there has been increased inflow onto the IB (presumably increased transfers), whereas the outflow has remained roughly constant. As inflow exceeds outflow, numbers on the IB have increased. Almost half of IB recipients receive the Accommodation Supplement (significantly less than SB recipients), and 75 per cent the Disability Allowance. ${ }^{30}$

Figure $3^{31}$

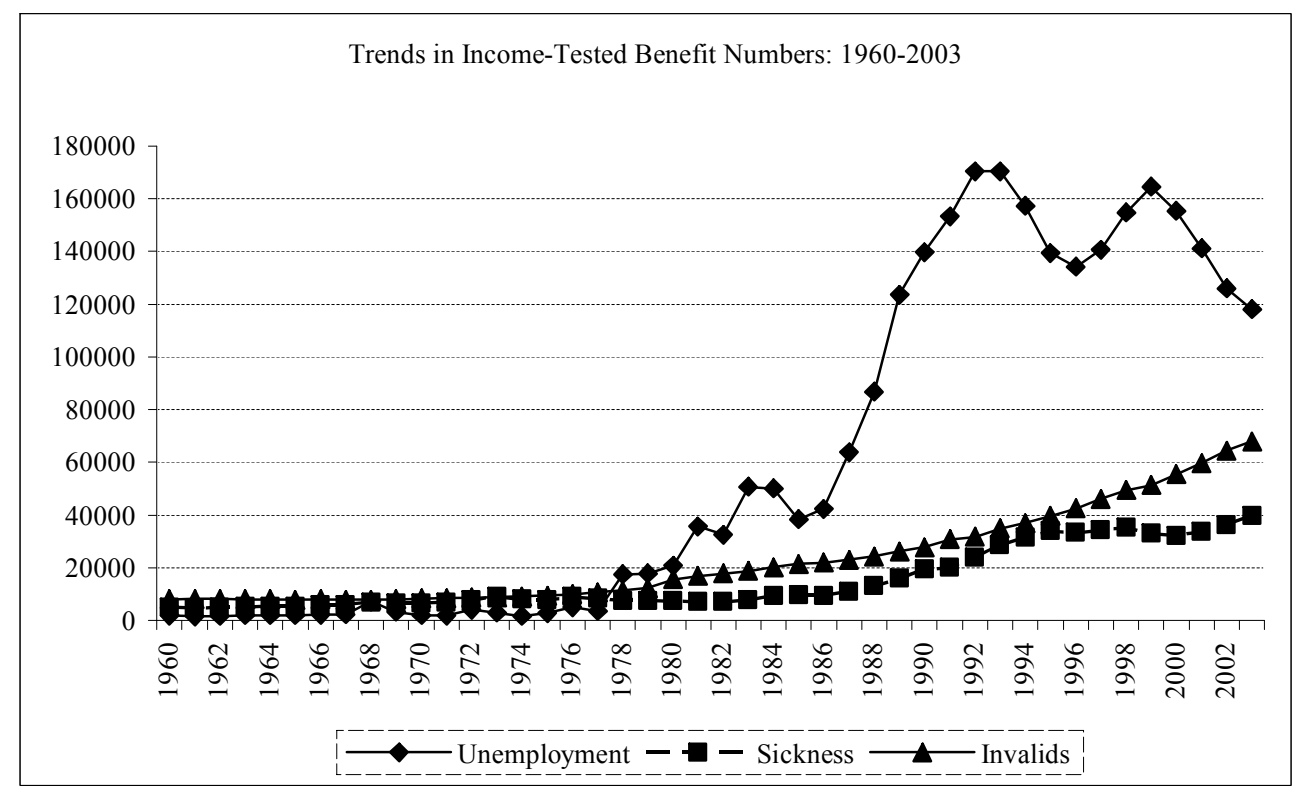

Figure 4 shows that the recent trends in ACC weekly compensation claims are different from those trends for the IB and the SB. Between 1995 and 2000, new claims for earnings-related compensation to ACC halved from almost 70,000 to 33,000, but have since risen to over 62,000 . The trend in ongoing claims follows the new claims but with a lag, so one would expect an upturn in the ongoing claims from 2004, though improved rehabilitation may curb future growth.

29 Derived from Ministry of Social Development, above n 21, 38-48.

30 Derived from Ministry of Social Development, above n 21, 38-48.

31 Ministry of Social Development, above n 21, 142. 
Figure $4^{32}$

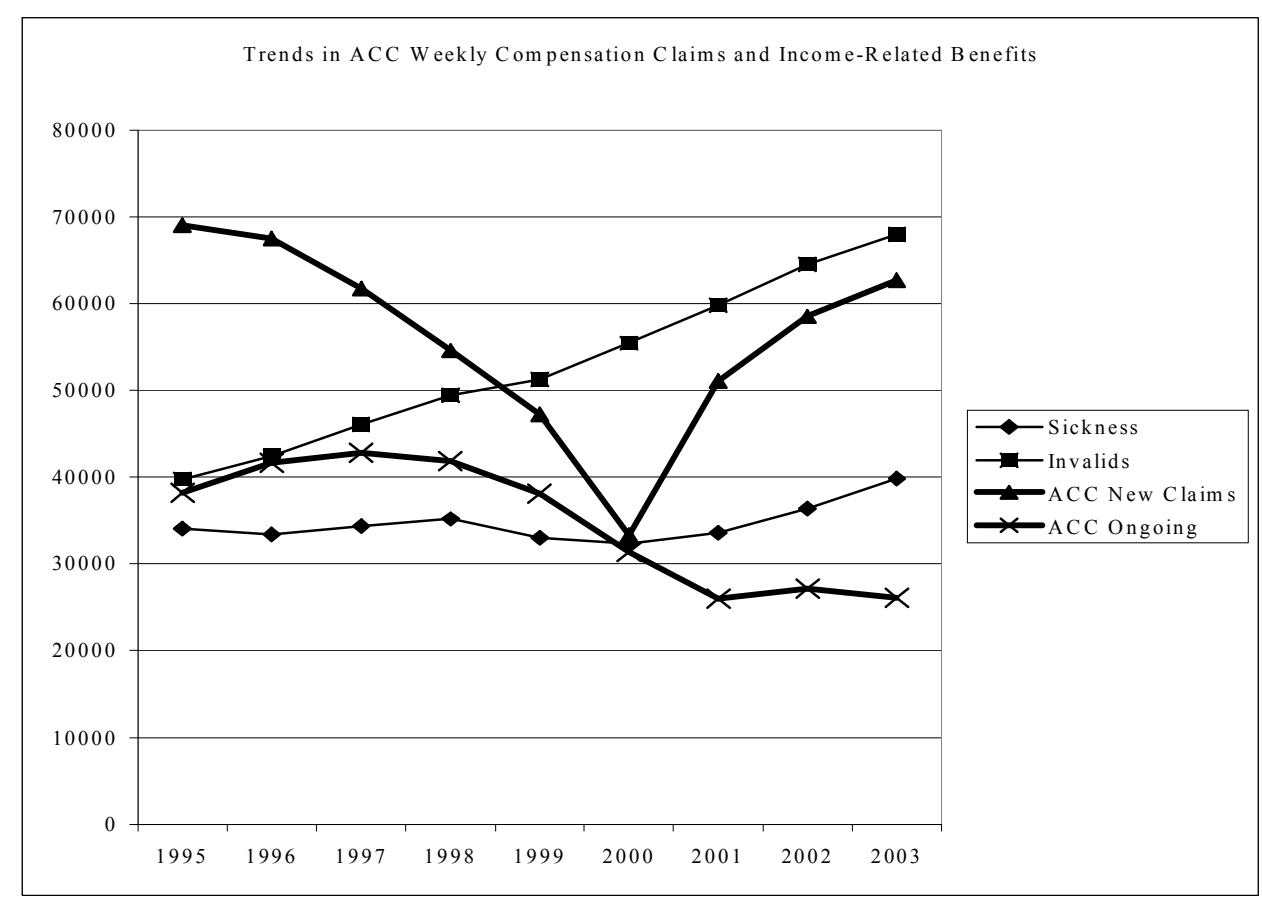

A variety of inter-related factors have led to the growth in numbers receiving incapacity payments over the last 30 years. These include:

(1) A growth in unemployment combined with a reduced willingness of employers to hire people with disabilities;

(2) An ageing of the population, as some forms of incapacity are age-related - almost half of the recipients of the IB are over 50 years, but only 30 per cent of SB are over 50 years of age ${ }^{33}$

(3) The increase in the age of entitlement to New Zealand Superannuation since 1992;

(4) An increase in the proportion of sickness and invalid beneficiaries with psychological and psychiatric conditions. However, the majority of psychiatric hospitals closed during the

32 ACC figures are derived from Accident Compensation Corporation $<\mathrm{http}: / /$ www.acc.co.nz $>$ (last accessed 22 November 2004); income related benefit figures are derived from Ministry of Social Development, above $\mathrm{n} 21,142$.

33 Ministry of Social Development, above n 21, 38-48. 
1980 s, and even then the majority of those in care were eligible to receive income-tested benefits;

(5) A tightening of eligibility for ACC has forced some accident victims into applying for the $\mathrm{SB}$ and the IB, although this impact is estimated to be small; and

(6) A lack of proactive case managers in WI, with case managers providing more resources for the unemployed than the more difficult to place IB/SB populations. However, the Jobs Jolt package announced in August $2003^{34}$ provides for the development of enhanced case management for the individual needs of $\mathrm{IB} / \mathrm{SB}$ populations, as well as the potential for increased employment opportunities through the disability employment service of Workbridge.

Offsetting these factors has been a tightening of eligibility criteria, with the requirement for designated-doctor reviews, a change in criteria to "permanently and severely" restricted rather than the current criteria of 75 per cent incapacity to work. Also there needs to be an alignment of the SB and the UB benefit levels to eliminate any financial incentive to switch between benefit categories.

\section{THE ISSUES}

Based primarily on length of impairment, it is possible to distinguish three groups of people affected by ACC/IB/SB, and who potentially face different forms of horizontal inequities. The first grouping have short-term injury or illness, where there is possibly no time off work, or any time off work is covered through sick leave provisions by the employer, but medical treatment is required. The second group can be defined as suffering "medium term" incapacity, in that time off work exceeds regular sick leave entitlement and treatment is more extensive than a visit to a general practitioner or physiotherapy appointment. The third grouping relates to more permanent incapacity, whether from birth, accident or degenerative illness, where lifestyle, including accommodation, needs to be adjusted to take account of the incapacity. This third grouping relates to any family (or extended family) member, whereas the first two groupings are more individual, though some caring provisions, especially for those with dependent children, may have to be made.

\section{A Employment}

A major issue that both $\mathrm{ACC}$ and the $\mathrm{SB} / \mathrm{IB}$ populations face is the low rate of employment for people with some form of incapacity compared to people without disabilities. Employment is seen as a major route out of poverty, and thus as a mechanism for satisfying the "belonging to and participating in" notion of well-being. Employment assists with social inclusion, providing a mechanism by which disabled people can live an "ordinary life".

34 "Jobs Jolt" (August 2003) MSD News Wellington 1. 
The top half of Table 1 misleadingly presents the employment rate for adults with and without disability, with the employment rate for disabled people only being marginally lower than those without disability. The issue is that the employment rate is calculated by dividing the number of people employed by the number in the work force. Included in the denominator (the number in the work force) are only those working or actively seeking work. The bottom part of the table looks at labour force participation rates, and shows both lower rates overall as well as a marked discrepancy between the two groups. The overall lower rate is due to the inclusion of the elderly in the analysis, but the comparatively lower rate for the disabled is a product of people with disabilities being in community participation programmes (and thus not seeking work) or being discouraged from seeking employment. ${ }^{35}$

Table $1^{36}$

(a) Employment Rate, with and without Disabilities, 1996 and 2001

\begin{tabular}{|l|c|c|}
\hline & 1996 & 2001 \\
\hline Adults (15+) with Disability & $92.3 \%$ & $90.8 \%$ \\
\hline Adults (15+) without Disability & $94.1 \%$ & $94.1 \%$ \\
\hline
\end{tabular}

(b) Labour Force Participation Rate, with and without Disabilities, 1996 and 2001

\begin{tabular}{|l|c|c|}
\hline & 1996 & 2001 \\
\hline Adults (15+) with Disability & $39.9 \%$ & $43.6 \%$ \\
\hline Adults (15+) without Disability & $70.0 \%$ & $69.8 \%$ \\
\hline
\end{tabular}

It should be recognised that employment, or rapid return to employment, may not be appropriate at all stages of life. Although 19 per cent of IB recipients and 7 per cent of SB recipients report parttime earnings, indicating some capacity to work, this may represent the extent of their current physical and mental abilities, or the difficulties in obtaining satisfactory employment. ${ }^{37}$ Many IB/SB clients have psychiatric or emotional problems, and full-time employment in the open-market may not be appropriate. However, social inclusion through participation and contribution to the workforce and society in general assists recovery from mental health problems. Individual assessment of the type, level and length of employment is needed, requiring active cooperation with

35 Saucier, above $\mathrm{n} 3$.

36 Based on the 1996 and 2001 Disability Surveys, Statistics New Zealand <http://www.stats.govt.nz> (last accessed 22 November 2004).

37 Ministry of Social Development, above n 21, 23. 
employers and Workbridge. Globalisation of the labour market and greater competitive pressures mean that many employers are reluctant to employ people with incapacities.

The level of and emphasis placed on rehabilitation services offered to ACC clients compared to those receiving the IB/SB probably means that the return to work for the ACC clients is faster: but an impression gained is of a sometimes over-zealous case management or use of the work-ready criteria. Some clients are probably taken too quickly off the ACC roll, and finish up on the IB/SB register. There is another group who are work-ready, but for a different, usually lowered paid, level of employment. ${ }^{38}$ The extent to which ACC should have a responsibility for maintaining clients' past earnings levels needs to be debated.

The issue is to ensure that those with some form of disability that compromises their ability to work or return to their former occupation, irrespective of cause of disability or administrative system, require similar access to case-managed employment services such as Workbridge and the State Service Commission's Mainstream Supported Employment Programme. In addition, a range of policy options need to be developed that will encourage employers to offer employment to those who may be physically or mentally unable to cope with full-time, full-year and full-capability work.

\section{B Benefit Levels}

There are significant differences in benefit entitlement and benefit levels between recipients of ACC and those receiving income-tested benefits. ACC payments are earnings-related, at 80 per cent of past earnings, but are only paid to those who have been full-time workers prior to the accident. ${ }^{39}$ There is no relationship to need (though the Invalids Benefit does provide such floor) but continuity of past living standards form the criteria. The benefit is paid to the individual suffering the accident, irrespective of their partner's income.

These payments are not adjusted for family size and circumstance, although the recipients are eligible for the family support tax credit based on their earnings-related benefit level, as well as being eligible for the Accommodation Supplement (although there will be an issue of take-up rates for those outside of the normal social security system). The benefit is of unlimited duration, although the medical requirements for continued receipt are fairly stringent. ACC payments are not abated with other income earned by a partner, though they are abated with own earnings. Lump-sum payments are available, with the level of payment related to the severity of injury rather than degree of need.

The income-tested IB/SB are flat-rate benefits, adjusted for family size and status with different levels of benefit depending upon age, spousal income and number of dependants. "Presumed level

38 Grant Duncan "Advancing in Employment: The Way Forward for Vocational Rehabilitation" (2004) 35 VUWLR 801

39 Accident Compensation Corporation <http://www.acc.co.nz> (last accessed 22 November 2004). 
of need" is the determining criterion for the level of payment, so that the benefit is abated against the income of the couple, where appropriate. However, the substantially higher payment for the IB compared to the SB, given the similarity of case load, is difficult to explain based on the need criterion. The imposition of the 15-hour rule for IB recipients seems anomalous given the abatement rate of 30 per cent for income between $\$ 80$ and $\$ 180$ per week and 70 per cent over $\$ 180{ }^{40}$ Variations in individual circumstances are taken into consideration through the provision of the Disability Allowance, although no evaluation seems to have been undertaken to ascertain take-up rates of the Allowance or its adequacy.

The major issue here is the choice between an earnings-related benefit, based on individual circumstances, or a flat-rate income-tested benefit. While this issue is well-traversed in the literature, ${ }^{41}$ any resolution for disabled people either causes downstream conflicts between the $\mathrm{SB} / \mathrm{IB}$ and the domestic purposes and unemployment benefits, or removes some of the founding principles of ACC. The criteria are not just fiscal costs and labour-market incentives but also social contracts and inter-generational equity.

Even if the flat- or earnings-related benefit issue finishes up in the too-hard basket, partial resolution may be feasible. First, the discrepancy in the unit of analysis should be overcome, with individual entitlement to the IB, irrespective of a partner's earnings, recognising that other family members often have substantial realignments of their lives if a disabled person is in the household. Second, similar encouragement to enter part-time work could be provided with similar abatement rates for additional earnings for both IB and ACC recipients. Third, equality of access to second and third tier social security benefits should be facilitated to improve take-up rates among ACC recipients of family assistance, Accommodation Supplement and the Disability Allowance.

\section{Access to Health Care}

One of the major perceived inequities that operates for all of the three groups relates to access to health care. Since 1997, ACC recipients have privileged access over other patients, both in terms of speed of service and payment levels to most medical practitioners. ACC will sometimes pay for accident victims to get surgery in the private sector if that provides a quicker return to work than being placed on a public hospital waiting list. ${ }^{42}$ ACC recipients receive heavily subsidised physiotherapy, general practitioner or dental treatment, for example, but only in relation to their specific accident. IB/SB patients can only claim the Community Services Card general benefit,

40 In the Working for Families package in the 2004 Budget this 15 hour rule was abolished.

41 See N Barr The Economics of the Welfare State (Oxford University Press, Oxford, 1999); Robert Stephens "Economics and Social Policy" in D Milne and J Savage (eds) Reporting Economics: A New Zealand Guide to Covering the Economy (New Zealand Journalists Training Organisation, Wellington, 1999) 189.

42 Accident Compensation Corporation <http://www.acc.co.nz> (last accessed 22 November 2004). 
which covers all primary health needs (although the difference will reduce as the Primary Health Organisation net is widened).

When work attendance is not affected, the rationale for the different treatment has limited justification. While there may be some sense in this differential access if the issue is a speedy rehabilitation back into the workforce, one still has to ask: Why should somebody doing a sedentary job with a sprained ankle from a rugby injury receive more rapid and cheaper treatment than a manual worker whose work capacity is affected by an in-grown toenail or arthritis?

If work attendance has been affected, the differential treatment seems more incongruous, especially if public funds are used for funding private health care treatment. Access to the public health system is based primarily on severity of need. However, since the 1997 change in ACC, ${ }^{43}$ only one-fifth of accident victims have been treated at public hospitals, but ACC claims that the extra $\$ 70$ million paid for elective surgery over the last six years has resulted in savings of about $\$ 4$ billion by clients getting back to work sooner. ${ }^{44}$ Delays in receiving surgery in public hospitals often result in individuals being forced onto the SB. Starting early-2004, the Ministry of Social Development will have a two-year trial scheme for IB/SB recipients in South Auckland similar to the ACC scheme. ${ }^{45}$

ACC patients have often been seen as queue-jumpers, diverting funds and resources from the public into the private health care system. Implicitly the ACC approach (and the Ministry of Social Development's trial) is based on ability-to-benefit from treatment, with benefit defined in terms of work effort rather than health per se. Using ability-to-benefit may be a sound philosophical and administrative approach to rationing the health dollar, and the ACC scheme seems to be a costeffective use of resources. All the same, the alternate rationing mechanism for the limited health dollar needs wide debate, especially given the likely switch of resources between public and private sectors.

\section{Rehabilitation}

The main focus of ACC is, correctly, on rehabilitation for work. The services provided, based on enhanced case management principles, represent an integrated approach to all forms of treatment (though some clients find the reality a little different). On the other hand, until the Jobs Jolt strategy in relation to disabled people is fully operative, those on the IB/SB have been more concerned with determining eligibility for the main and supplementary benefits than employment rehabilitation.

43 St John, above n 20, 176.

44 M Lowe "Waiting for Surgery no Longer a Reason for ACC" (25 January 2004) Sunday Star-Times Auckland 3.

45 St John, above n 20, 176. 
Access to rehabilitation services have often been required, but with insufficient priority given to that form of social investment.

Under ACC, there is a recognition that workforce rehabilitation is not always feasible or complete. Some effort seems to occur in reorienting the injured person's lifestyle. However, as Duncan reports, there is an issue of whether these incomplete rehabilitation people finish up on the IB/SB roll. ${ }^{46}$ ACC does not always follow up on claimants who have been rehabilitated and whose compensation has been terminated, to see whether they have returned adequately to their former employment.

Extending the ACC range of integrated rehabilitation services and case management approach to all IB/SB recipients, where appropriate, would provide horizontal equity and most likely would be a cost-effective use of resources. The Disability Strategy, the establishment of the Office for Disability Issues and the initiation of the Jobs Jolt package represent excellent first steps. Whether the ACC organisational structure could be extended to cover the wider and more diverse clientele or a separate agency developed would need to be carefully evaluated.

\section{E On-going and Set-up Costs for Disability}

People with disabilities tend to face additional costs compared to able-bodied people, with these costs associated with the nature of the disability. Thus any benefit system that is designed to offset need (including ACC recipients with the fall-back option of the IB) will require a base-line benefit for normal living $\operatorname{costs}^{47}$ plus extra allowances for disability-specific costs. The extra allowances can be simply split into set-up costs, to adjust the home or life-style to the disability, and on-going or regular costs faced by disabled people. All of these costs are case-specific, but are also dependent on the length of time of the disability plus the costs of realigning the home environment with the level of achievable lifestyle. Discretionary case-management is required to calculate the level and form of any additional benefit.

The current Disability Allowance for IB/SB recipients reimburses people for actual and ongoing regular costs that they incur because of their disability or personal health need. These costs must be likely to last for six months, though it may be sensible to offer support, such as taxis to work, along ACC lines, for people with short-term disabilities. One issue is whether the same approach should be made for ongoing disability costs, but it would seem sensible to investigate the rationalisation of these provisions.

46 Duncan, above n 37.

47 The current level of payment for IB and SB is the result of history, political compromise and trade-off with other objectives such as fiscal costs and labour force incentive effects. There has been no attempt to ascertain the adequacy of the benefit through the development of a minimum budget standard or to ascertain how beneficiaries cope on the benefit: C Waldegrave, Robert Stephens and P King "Assessing the Progress on Poverty Reduction" (2003) 20 Social Policy J NZ 197. 
Adjusting homes and lifestyles (for example, provision of a wheel-chair) is another issue where unified rules and payments would provide horizontal equity, and state funding of these additional costs should be based on the issue of social justice. At present the lifestyle adjustment is done more automatically under ACC than for IB/SB recipients. There also seems to be a greater requirement for self-funding for IB/SB recipients for these set-up costs than under ACC rules.

\section{F Funding}

The differences in the funding mechanisms are just as significant as the forms and levels of benefit payment. The philosophy underpinning social security is a separation of payment based on need from funding based, in part, on ability to pay. The IB and SB are totally funded from general tax revenue on a pay-as-you-go basis. Current expenditures are funded from current tax revenue, with no fund build up for contingent liabilities from existing or past events.

ACC's funding, on the other hand, is more closely related to the benefit principle of taxation, where the tax charge is directly related to the expected benefit (or in the case of ACC related to the expected actuarial cost and incidence of accidents). ACC is funded from seven separate accounts, each with their own funding rules and levies, with funding designed to cover current and contingent claims liabilities. Except for the non-earners' account, which accounts for almost a quarter of total levy income of $\$ 2,574$ million and 16 per cent of total claims liability of $\$ 9,155$ million, the rest of ACC expenditure is off-budget. ${ }^{48}$

At present, the distinct sources and philosophies behind the different funding mechanisms are not an issue of contention. If benefit payments are integrated, then the issue of general or specific source of funds will become problematic. One possible solution would be to integrate the nonearners' account with the IB/SB. Only if all income-tested benefits become earnings-related would it be possible to have funding based on individual contributions, but that would still not address the anomalies with the multiple sources of ACC funding, especially the employers' account, nor address the issue of risk rating and incentives inherent in ACC premiums that would either be inequitable or infeasible for income-tested beneficiaries.

With the population ageing, because the incidence of disability increases with age, the unfunded IB/SB schemes will face increased expenditures in the future. ACC may not face quite the same financial pressure from ageing as work accidents are more related to occupation than age, and vehicle accidents have a greater incidence among younger age groups. However, disability and accidents are likely to be a relatively small aspect of the additional costs from an ageing population.

48 Accident Compensation Corporation Annual Report 2003 (Accident Compensation Corporation, Wellington, 2003). 


\section{CONCLUSIONS}

Despite 30 years of operation and sporadic discussion on integration, ACC and the IB/SB are still run and operated as separate benefit systems. However, from the perspective of the disabled, the major inequity lies in the differential access to non-income support such as access to equipment, health care, education and employment.

The issue has generally been seen as the horizontal inequity between the earnings-related ACC payments and the flat-rate benefits of the $\mathrm{IB} / \mathrm{SB}$, and the related funding mechanisms. The different philosophical basis for social insurance, based on contributory principles and preservation of existing status, cannot be directly compared with social assistance based on citizenship and the avoidance of hardship. Switching the IB/SB to an earnings-related approach would have significant fiscal costs and the major beneficiaries would be the higher paid. Non-earners would be losers and the anomaly would then switch to the SB/UB boundary as both groups have close relationships with work.

Both systems have separate and distinctive clients, with ACC only considering accident victims whereas the majority of the IB/SB population have psychiatric or medical disorders, though some victims of accidents are also recipients. However, the medical outcome is often similar, with extended periods off work and the need for regular care and attention, and adjustments of family lifestyles to accommodate the accident or medical condition. The differential access to health care related treatments between $\mathrm{ACC}$ and $\mathrm{IB} / \mathrm{SB}$ clients, and the related cost disparities, represent a major inequity. Although improvements in service delivery for ACC clients can undoubtedly be made, the integrated nature of service delivery represents a major advantage over the experience of IB/SB clients. A case for combining service delivery can be made on cost-effectiveness criteria, and this will assist the achievement of the Disability Strategy goals of a consistent, timely, holistic and flexible system.

While the majority of those affected by disability only have a temporary incapacity that requires no alteration to one's long-term lifestyle, others have a more permanent incapacity. There are invariably additional costs related to the specific nature of each person's incapacity, and much of this will not be able to be covered by the general benefit payments. The additional costs may be ongoing, relating to the continuing need for care or diet and set-up costs - altering homes, for example - to take account of the nature of the disability. Again, there is a case for investigating the combined provision of these benefit add-ons for all forms of disability, rather than separate determination.

The development of the Disability Strategy will hopefully provide a greater degree of horizontal equity in treatment of all disabled people. Rather than starting with a uniform benefit payment system, this paper suggests that attention be first placed on assisting access to work, ensuring equity in service delivery and then ensuring that the specific add-on costs be integrated and made on transparent, consistent and coherent criteria. 